\title{
Phenotypic variation in familial chilblain lupus $(F C L)$ and Aicardi-Goutières syndrome (AGS) associated with TREX1 mutation in 4 family members
}

\author{
James Glanville ${ }^{1 *}$, Saleem Taibjee ${ }^{2}$, Yanick Crow ${ }^{3}$, Penny Davis ${ }^{1}$, Clive Ryder ${ }^{1}$, Taunton Southwood ${ }^{1}$ \\ From 18th Pediatric Rheumatology European Society (PReS) Congress \\ Bruges, Belgium. 14-18 September 2011
}

\section{Background}

The spectrum of clinical manifestations associated with mutations of the TREX1 gene (a major human 3'-5' exonuclease which is an essential negative regulator of autoimmunity) includes systemic lupus erythematosus, FCL, AGS and retinal vasculopathy with cerebral leukodystrophy.

\section{Aim and Methods}

To further define the clinical spectrum associated with TREX1 mutations by reporting a series of cases from a single family.

\section{Results}

The index case was a 10 year old Afro-Caribbean boy who initially presented with a non-progressive developmental delay and severe chilblains (the chilblains improved with methotrexate). He developed transient acute ataxia and flattened affect, with visual and auditory hallucinations. Parotid swelling, arthritis and proximal myopathy were noted, but autoantibodies were negative and complement studies normal. No viruses were detected in CSF or saliva. EEG was consistent with encephalopathy. Cerebral MRI was normal but basal ganglia calcification was seen on CT. Skin histology was consistent with FCL.

His mother and 2 siblings ( 3 year old brother and 6 year old sister) also had chilblains (each child had a different father). No other family member had developmental delay, other evidence of autoimmunity or inherited metabolic disease. Neither sibling had CT evidence of basal ganglia calcification. All 4 affected family members had heterozygote mutation of the TREX1 gene (p.Asp18Asn).

\section{Conclusion}

FCL is a genodermatosis characterised by painful bluishred skin lesions. AGS is a progressive, chronic encephalopathy associated with basal ganglia calcification. FCL and AGS are proposed to be different clinical manifestations associated with a variety of TREX1 mutations. Our cases demonstrate the variation in clinical phenotype associated with a single TREX1 mutation, ranging from typical FCL to acute encephalopathy with features suggestive of AGS, in 4 family members.

\section{Author details}

${ }^{1}$ Department of Paediatric Rheumatology, Birmingham Children's Hospital,

UK. 'Department of Dermatology, Birmingham Children's Hospital, UK.

${ }^{3}$ Department of Genetic Medicine, St Mary's Hospital, UK.

Published: 14 September 2011

doi:10.1186/1546-0096-9-S1-P283

Cite this article as: Glanville et al:: Phenotypic variation in familial chilblain lupus (FCL) and Aicardi-Goutières syndrome (AGS) associated with TREX1 mutation in 4 family members. Pediatric Rheumatology 2011 9(Suppl 1):P283.

\footnotetext{
* Correspondence: james.glanville@doctors.org.uk

'Department of Paediatric Rheumatology, Birmingham Children's Hospital, UK

Full list of author information is available at the end of the article
} 